\title{
SINKHOLE PHYSICAL MODELS TO SIMULATE AND INVESTIGATE SINKHOLE COLLAPSES
}

\author{
Mohamed Alrowaimi \\ Doctoral Student, Civil, Environmental and Construction Engineering, University of Central Florida, \\ 4000 Central Florida Blvd., Orlando, Florida, 32816, USA, alrowaimi@knights.ucf.edu
}

Hae-Bum Yun

Assistant professor, Civil, Environmental and Construction Engineering, University of Central Florida, 4000 Central Florida Blvd., Orlando, Florida, 32816, USA, Hae-Bum.Yun@ucf.edu

\section{Manoj Chopra}

Professor, Civil, Environmental and Construction Engineering, University of Central Florida

4000 Central Florida Blvd., Orlando, Florida, 32816,USA, Manoj.Chopra@ucf.edu

\section{Abstract}

Florida is one of the most susceptible states for sinkhole collapses due to its karst geology. In Florida, sinkholes are mainly classified as cover subsidence sinkholes that result in a gradual collapse with possible surface signs, and cover collapse sinkholes, which collapse in a sudden and often catastrophic manner. The future development of a reliable sinkhole prediction system will have the potential to minimize the risk to life, and reduce delays in construction due to the need for post-collapse remediation. In this study, different versions of smallscale sinkhole physical models experimentally used to monitor the water levels in a network of wells. This information is then used in a spatial-temporal analysis model to study the behavior of the system until the sinkhole collapses. The ultimate goal is to use this process in a reverse manner to monitor an existing network of installed groundwater wells to study the fluctuations in the water levels and use the spatial-temporal analysis to predict potential sinkhole collapses. The groundwater levels are monitored using sensors that are hooked up to a high-resolution data acquisition system. The results of a series of tests conducted using this sinkhole physical model showed that there is a very distinguishable groundwater cone of depression that forms underground before the sinkhole collapses. This cone of depression was studied in its early stages and as it progressed with time. This analysis is used to then investigate the growth of the sinkhole before the surface eventually collapses. The spatial-temporal model showed the development of the groundwater cone of depression with time during the development of the cavities within the sediments can be used as a potential 'signal' to identify and isolate the sinkhole location.

\section{Introduction}

Sinkhole is a ground surface depression that occurs with or without any surface indication. Sinkholes commonly occur in a very distinctive terrain called karst terrain. This terrain mainly has a bedrock of a carbonate rocks such as limestone, dolomite, or gypsum. Sinkholes develop when the carbonate bedrocks are subjected to dissolution with time to form cracks, conduits, and cavities in the underground bedrock. These features allow the overburden soils (on top of the carbonate bedrock) to transport through them to the underground cavities, which results in surface collapse due to the upward progression of the soil cavity toward the ground surface. Sinkholes vary in shapes and sizes. They have different shapes such as inverted cone, shallow bowl, and shaft shapes. Also, they can range from less than a meter to hundreds of acres and from $30 \mathrm{~cm}$ to 30 meters in depth (Waltham et al., 2005).

Sinkholes can be formed due to several processes such as bedrock dissolution, soil suffosion, rock collapse, and soil collapse. Based on the formation processes, sinkhole generally can be classified to six types: Solution (Dissolution) sinkholes, Collapse sinkholes, Caprock sinkholes, Dropout (Cover-collapse) sinkholes, Suffosion (Cover-subsidence) sinkholes, and Buried sinkholes (Lowe and Waltham, 2002) (Williams, 2004) (Waltham et al., 2005).

\section{Background}

The state of Florida is one of the most susceptible places to sinkholes in the United States due to its geology. Florida's karst geology is underlain by carbonate deposits, which is continuously subjected to a dissolution 
process due to the circulation of the groundwater (Atkinson, 1977) (Quinlan et al., 1993) (Tihansky, 1999). The dissoluble carbonate bedrock is overlain by several layers of sand and clay soils. These clay and sand sediments vary in thicknesses based on their location within Florida (Bottrell et al., 1991). Florida's sinkholes are mainly classified into three types: dissolution sinkholes, cover-subsidence sinkholes, and cover-collapse sinkholes. All of these types are the results of one or both of the dissolution and suffosion processes. The dissolution process is the chemical process where the carbonate rock dissolves due to the exposure to acidic water forming cracks, fissures, conduits, and cavities in karst. While, suffosion is a physical process of transporting the unconsolidated soil sediments to the bedrock's underground cavities through the existing cracks and conduits (Sinclair and Stewart, 1985) (Tihansky, 1999).

Florida's climate has a very distinctive two seasons (dry and raining seasons). The groundwater reaches its highest level in the end of the raining season (September). However, this level decreases until it reaches its lowest level at the end of the dry season (May). This kind of groundwater seasonal variation is one of the most important factor that triggers sinkhole collapses in Florida (Lewelling et al., 1998) (Sinclair, 1986) (Tihansky, 1999).

\section{Problem Statement}

Sinkhole prediction is a complex task due to the combination of different factors (geological and hydrological factors) involve in forming sinkholes. There is a broad field of the ground investigation techniques that can be used to investigate possible sinkhole locations. These techniques can be direct investigation by using soil probing, poring, drilling and sampling, or indirect investigation by using either geophysical methods or aerial or satellite remote sensing. The problem with the direct methods is that the borehole can easily miss a progressing underground cavity. Besides that, sinkhole history maps, and aerial and satellite remote sensing are not providing assurance that all the surface depressions (subsidence) detected by these methods are actually sinkholes (Waltham et al., 2005). No single method works in all situations, and an integrated approach must be adopted. As a part of this integrated approach, we studied the relationship between groundwater levels and sinkhole collapse.

\section{Research Scope}

The motivation behind the present research was to find a 'sign' to guide the ground investigation team to the potential hazardous area of sinkholes based on existing information such as groundwater levels. Since groundwater change is one of the main driving forces to cause and accelerate sinkholes in Florida, it is anticipated that the indication of the sinkhole collapses may be noted in the groundwater behavior before the surface collapse occurs. Hence, a small-scale physical model was designed and built to naturally simulate sinkholes. This model is a spatial-temporal model type. It was mainly designed to monitor the groundwater fluctuations around a predetermined sinkhole. The monitoring wells were radially distributed around the sinkhole in the physical model.

The model was initially designed based on a typical profile of Florida's karst hydrology and geology. An important assumption in this test was that the dissolution process has taken place previously. In this model, the dissolution fracture is represented by a circular hole that transports a certain volume of soil through the limestone to an underground cavity. Moreover, this spatialtemporal model was designed to simulate a period of time at the end of the dry season in Florida (May), where the groundwater drops to its lowest levels. In general, the model is used to study the relationship between the groundwater fluctuation and sinkholes' formation, location, and time.

\section{Previous Work Sinkhole Models}

A discussion on previous research on sinkhole soil models is presented in this section. In the past, some models were implemented using different approaches such as centrifuge models, analogical models, and actual soil physical models (Abdulla and Goodings, 1996) (Goodings and Abdulla, 2002) (Chen and Beck, 1989) (Caudron et al., 2006a, 2006b) (Caudron et al., 2008) (Lei et al., 1994) (Lei et al., 2005).

In 1989, Chen and Beck designed a two dimensional soil model to study the mechanisms of sinkholes. They used layers of natural sediments, which were tested in a parallel-plate type tank with a bottom opening. This tank has wooden bottom and Plexiglass sides. Chen and Beck (1989) simulated 23 different trials of homogeneous and stratified soils with initial conditions of dry, partially 
saturated, or saturated. This simple model was designed to simulate a cover-collapse sinkhole. The objective of this study was to obtain some data about the sinkhole's mechanical processes which were not known at that time. In this model, the authors found that type of the sediments, namely sand or clay, controls the time of the collapse. Also, the initial conditions of the sediments, such as dry, saturated, or partially saturated varies the speed of the sinkhole development. The model also proved that in the stratified overburden, the collapse may stop when a cohesive stratum is encountered at the top of the opening. This will cease the internal erosion either permanently or temporarily. While this qualitative two-dimensional soil model is a very simple model, however it can provide some basis for more sophisticated quantitative physical models of sinkhole to be developed (Chen and Beck, 1989).

Finally, a large-scale experimental study of sinkhole physical models was conducted by the Institute of Karst Geology in China (CAGS) in 1997. The model was aimed at studying the factors that control the formation of a sinkhole (Lei et al., 1994, 2002, 2005). CAGS's physical model consists of three main components that are a base unit, recharge-discharge system, and observational system. It is a large-scale model with dimensions of 3 $\mathrm{m}$ in height, and $2 \mathrm{~m}$ in both depth and width (Lei et al., 1994, 2005).

Next, Lei and others, in 2005, simulated certain sinkhole formations in Hongshan District by using two conceptual models. This study investigated the effects of the width of limestone cracks, rate of water pumping, and mudstone thickness (the mudstone layer is located on the top of the limestone). It was concluded that groundwater pumping triggers more sinkhole collapses. In addition, the cracks in the limestone have a direct relation to the voids in the soil sediments in terms of size. Finally, it was noticed that the rate of the declination of groundwater is an important factor in the sinkhole collapse (Lei et al., 2005).

\section{Sinkhole Evaluation Based on Groundwater Recharge}

In 1994, Foshee and Bixler conducted a study of coversubsidence sinkholes in Florida. The development of sinkholes around State Road 434 and Harbor Isle intersection in Seminole County, Florida, caused minor pavement settlement for that intersection. Seven different sinkholes occurred north and south of State Road 434.
These sinkholes also caused settlements to building, roads, and yards. Hence, the Florida Department of Transportation (FDOT) decided to monitor the pavement settlement for State Road 434 to evaluate potential causes. A subsoil explorations program was conducted by using several cone penetrometer tests and the installation of permanent piezometers. The data evaluation of this study showed that there was a layer of very loose soils located at deeper ground strata. This loose soil was subjected to internal soil erosion (raveling). This raveling soil migrates slowly through limestone cracks to underground cavities and conduits in the carbonate bedrock. Eventually, this raveling process ends with a surface depression called cover-subsidence sinkhole. The main driving force of this raveling process is the downward groundwater movement, which is called recharge. This recharge occurs because of the difference in the shallow water table and the confining aquifer water level if recharge points exist which are the bedrock cracks. Recharge was observed in this site by studying the piezometer reading for almost two years. However, in this study, only piezometer readings at a specific time intervals were plotted as contour maps. The piezometer head contours showed a very clear depression indicating the settlement location. Foshee and Bixler (1994) stated that studying sinkholes by the pore-pressure-contouring technique should be further investigated to validate the reliability of this technique in different types of subsurface soil conditions.

\section{Current Sinkhole Physical Model}

This current study's main objective is to conduct a spatial-temporal analysis for network of groundwater monitoring wells to try and predict the location of a sinkhole collapse. In reverse analysis, a network of wells were distributed in a radial distances around a predetermined sinkhole location. Sensor devices were chosen and programmed to detect the water level fluctuations with a high degree of accuracy. The water level was monitored at $0.5 \mathrm{~mm}$ resolution. The data was also collected at a high sampling rate of $100 \mathrm{~Hz}$.

Due to the lack of initial research funds, a simple 55-gallon metal drum to be used (56 cm diameter) for testing. A $5 \mathrm{~mm}$ circular hole was drilled at center of the base of the drum. This hole represented a crack or a collection of close cracks in the limestone bedrock. The purpose of this circular hole was to transfer a certain volume of soil sediment out of the model to mimic the loss of soil 
through a limestone crack at a slow rate. Initially, the challenges encountered were related to the small-scale physical simulation of a sinkhole and the scaling of all the controlling parameters. These controlling parameters are the soil depth (overburden soil thickness on top of the limestone), location of the groundwater to cause sinkholes, artificial rainfall intensities, side (edge) effects on the development of the sinkhole, and the size of the base opening. The side effect was one of the most important factors, since the sides should not control or interfere in the sinkhole formation and development zone. All these parameters were finally selected based on a series of initial tests. The results of these tests are not included in this paper, but were critical in finding the proper scale for the sinkhole simulator.

The sinkhole simulator included a network of eight groundwater monitoring wells. These monitoring wells were distributed in a radial manner around the center, which was the predetermined location of the eventual sinkhole. Figure 1 shows the radial distribution of the eight monitoring wells. Each monitoring well was made of a one-inch PVC pipe. These pipes were perforated all around to allow the water to enter. The pipes were then wrapped with a geotextile fabric to allow only the water to pass and filter the soil particles. Eventually, every PVC pipe (well) was equipped with a 12 Inch eTape Liquid Level Sensor (MILONE Technology). The PVC pipes were also used to maintain the sensors in vertical orientation during the test to achieve the highest accuracy of their results. The sensors were used to read the actual water levels at the eight monitoring wells. The locations of the monitoring wells were set to be at the following distances $(10 \mathrm{~cm}, 12 \mathrm{~cm}, 14 \mathrm{~cm}, 16$ $\mathrm{cm}, 18 \mathrm{~cm}, 20 \mathrm{~cm}, 22 \mathrm{~cm}$, and $26 \mathrm{~cm}$ ) from the center of the test as shown in Figure 1. These locations were chosen based on a series of tests to make sure that they are far enough from the sinkhole failure zone. This assures that the closest pipes will not influence the formation, spread and collapse of the sinkhole cavity. A cross-section of the sinkhole simulator is also shown in Figure 1.

In this study, a sandy soil with $1 \%$ passing the 200 sieve from Orlando, Florida, was chosen for the physical model. This soil was classified as a dark brown fine sand (AASHTO type A-3). The soil had an optimum moisture content of $13 \%$, a maximum dry unit weight of $104 \mathrm{lb} /$ $\mathrm{ft}^{3}$, and a specific gravity of 2.6. The first step in the test was to seal the opening (limestone crack) using a rubber sheet in the bottom of the metal drum. Then, the pre-cleaned sandy soil with a moisture content $13 \%$ was well compacted in soil mold. Prior to adding the soil, the eight PVC pipes (monitoring wells) were installed at the radial locations shown in Figure 1. The thickness of the soil layer was varied between $150 \mathrm{~mm}$ and $200 \mathrm{~mm}$. The soil layer was fully saturated to a depth of $22.5 \mathrm{~mm}$ and $30 \mathrm{~mm}$ from the ground surface, respectively, for a period of 24 to 48 hours. These levels represent the shallow water table in the soil sample.
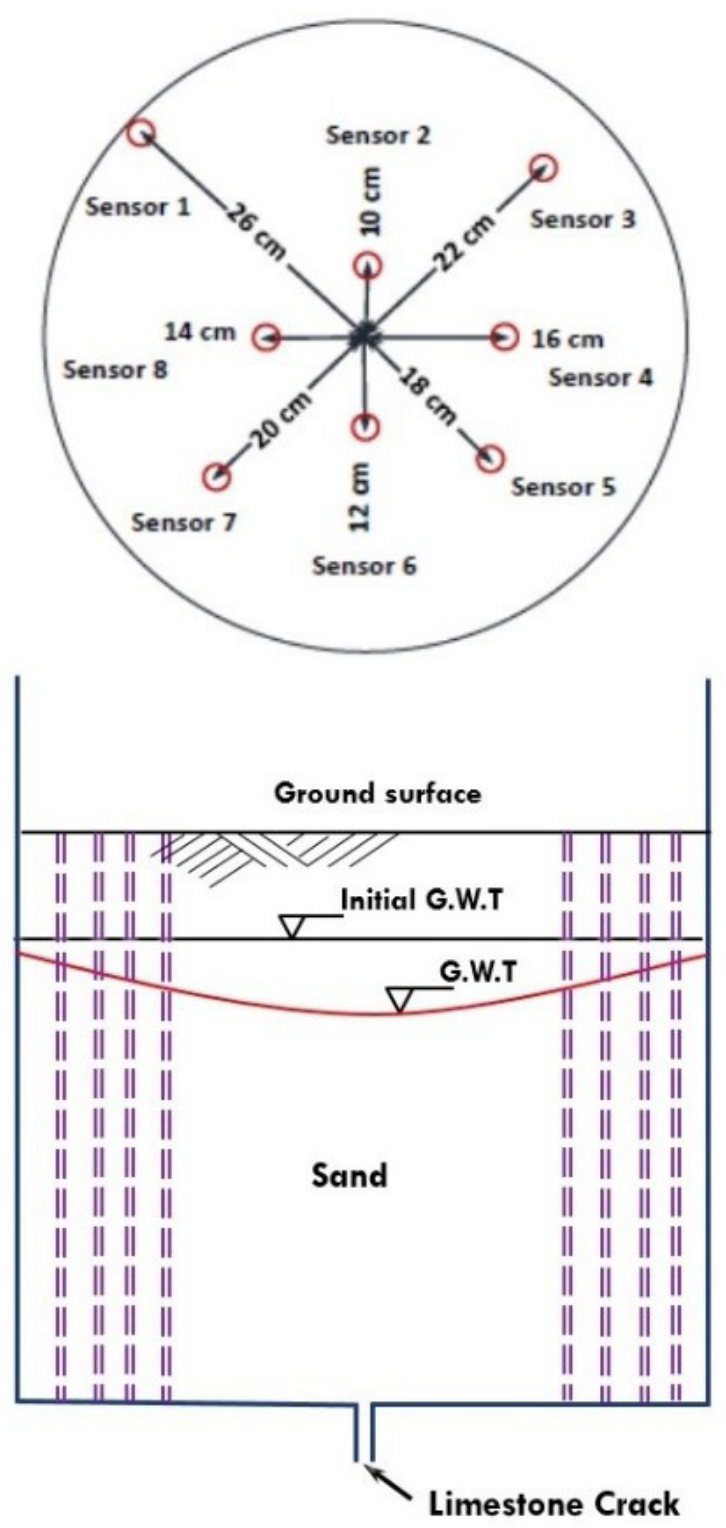

Figure 1. The Radial Location of the Eight Monitoring Wells and Physical Model Crosssection. 
The data acquisition system used in this study consists of an NI PXIe-1062Q module from National Instruments, Labview software, and 12" eTape Liquid Level Sensors from MILONE Technology. The NI PXIe-1062Q module was hooked up to the eTape sensors with a voltage divider circuits. This DAQ system was coded using the Labview program to read a very sensitive water level fluctuation of up to $0.5 \mathrm{~mm}$ with high sampling rate of 100 readings per second. Figure 2 and 3 show the sinkhole experimental model setup picture and diagram, respectively. After the full saturation stage to the desired groundwater level, the eTape sensors were dropped in the monitoring wells. The DAQ system then was turned on to start reading the water level fluctuation. After approximately 3 to 8 minutes, the hole was opened. This represents the transport of the soil through the limestone crack/s to the underground limestone cavities. Finally, the soil was left to behave naturally due to the drops of the shallow groundwater until a collapse representing a sinkhole occurred on the ground surface as shown in Figure 2.

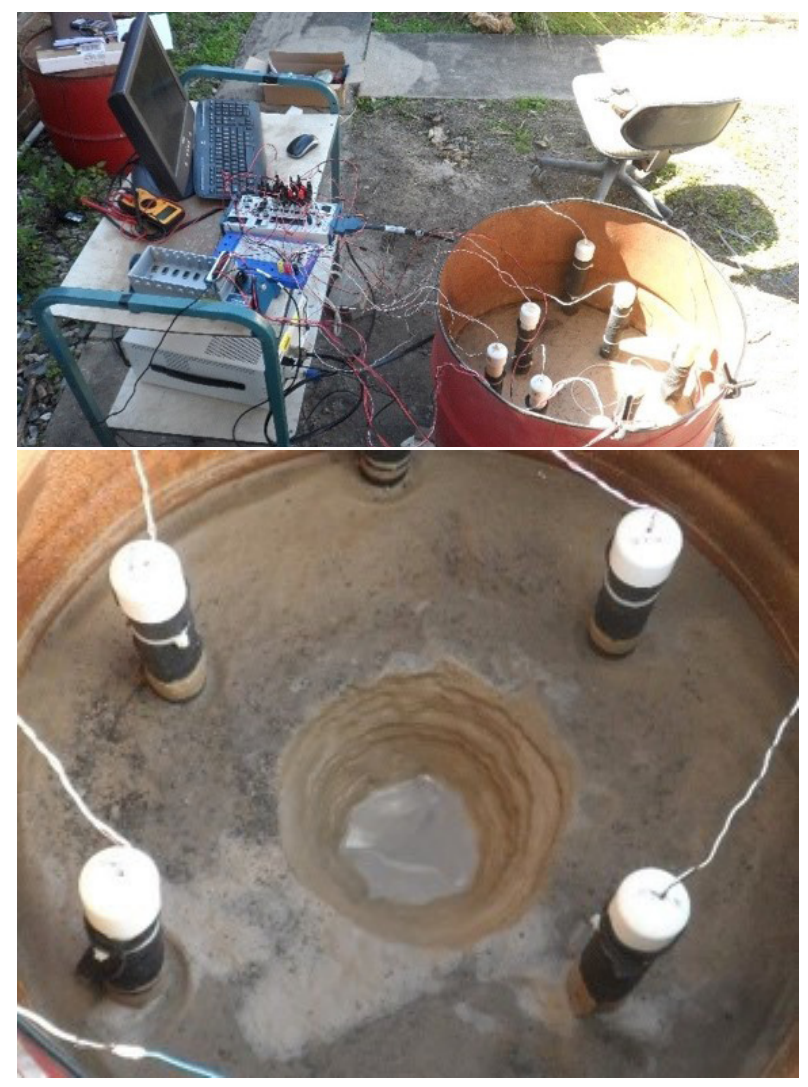

Figure 2. Sinkhole Physical Model Test Setup and sinkhole collapse.

\section{Results and Discussion}

In this study, more than 30 model configurations were tested. However, the results of only four different tests are presented in this paper. The first two tests were with soil thickness of $150 \mathrm{~mm}$ (representing the overburden soil above the limestone bedrock) and with initial groundwater level at $22.5 \mathrm{~mm}$ from the ground surface. While, the other two tests were with a $200 \mathrm{~mm}$ soil thickness and an initial groundwater level of $30 \mathrm{~mm}$ from the ground surface. This sinkhole physical model is designed to run a sensitive spatial-temporal analysis by using a dense network of water level sensors to read the groundwater fluctuation with high resolution $(0.5 \mathrm{~mm})$ high sampling rate $(100 \mathrm{~Hz})$. The sinkhole occurred after 16.0, 19.7, 20.0, and 26.6 minutes in TEST 1, TEST 2, TEST 3 , and TEST 4, respectively.

The results of TEST 1, 2, 3, and 4 are plotted in Figure 4 to illustrate the groundwater drops with time. These figures also show the effect of the radial locations of the eight monitoring wells prior to the sinkhole collapse. It was observed in all tests that the groundwater drawdown was faster in the wells closer to the predetermined sinkhole location than the wells further away from the center. This natural phenomenon is called the cone of water depression. In all tests, the cone of depression developed well before surface collapse occurred. It is also observed that the cone of depression gets steeper with time as the underground cavity within the sediments gets bigger.

In order to see the development of the groundwater cone of depression, the groundwater drawdown was plotted against the eight radial locations of the monitoring wells (i.e., $10 \mathrm{~cm}, 12 \mathrm{~cm}, 14 \mathrm{~cm}, 16 \mathrm{~cm}, 18 \mathrm{~cm}, 20 \mathrm{~cm}, 22$ $\mathrm{cm}$, and $26 \mathrm{~cm}$ distances from the sinkhole location). Figure 5 shows these plots for TEST 1 and TEST 2. It can be seen in Figure 5 (a, b, and c) that there is a very distinctive water cone that starts right after the initiation of the sinkhole formation by opening the bottom hole. The top of this inverted cone is pointing toward the sinkhole location and also its slope gets steeper as time gets closer to the sinkhole collapse. It is also observed that some of the water level sensors might not follow the sequence of the drop in the water level, which implies that a closer sensor shows a higher water level than a more distant sensor. This kind of behavior is possibly due to the inability of having a very homogenous soil all around the sample, since compaction level may vary somewhat within the same soil. However, the general trend of the 


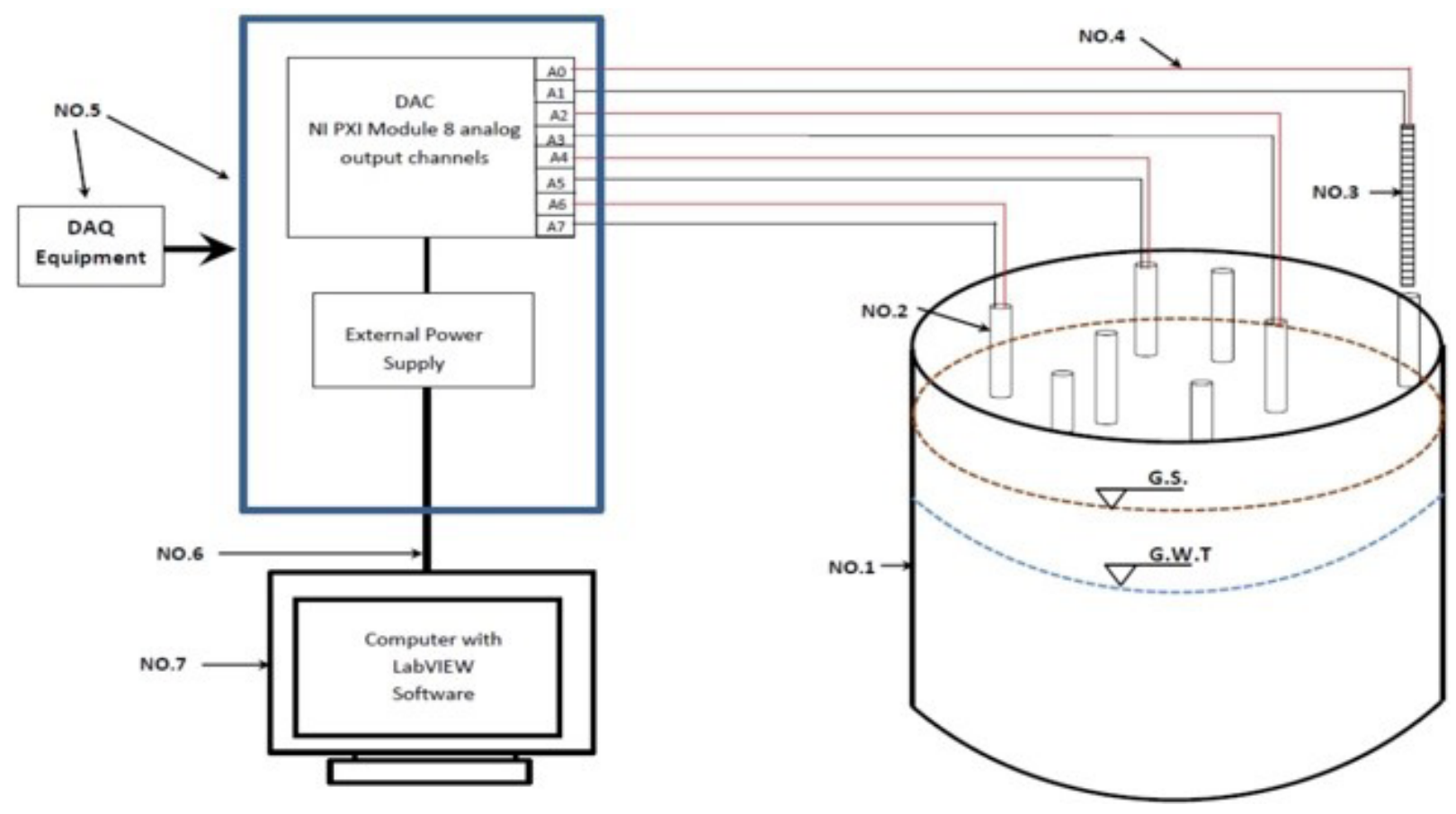

Figure 3. Sinkhole Experimental Model Setup Diagram.

groundwater drawdown forms a very distinctive cone of depression, which can point to the potential location of a sinkhole that is developing underground.

During all tests, the sensor water readings showed distinctive progressive drops with time. The progressive drops were analyzed to investigate their relationship to the sinkhole collapse location and time. Only the results of TEST 1 were chosen to illustrate this behavior in this paper. As it is seen in Figures 6 and 7, there were progressive and sudden drops in the groundwater table. These drops start after initiating the sinkhole (by opening the hole) and then transferred from the nearest sensor to the sinkhole to the second nearest sensor with a time lag. These drops can be observed to move from the closer sensors to the further sensors with time. This behavior of the sudden drops of the groundwater level was also observed on the experiment display screen during the test, when the soil has a faster rate of sediment loss out of the bottom hole. This means that the progressive drops are representing a certain internal collapse of the cavity within the sediments. Also, the amplitude of the progressive drops is related to the rate of sinkhole formation. Thus, the progressive drops of the groundwater table can serve as an indicator for the potential location of sinkhole.
To avoid the overlap of the sensors data, only some selected sensors are studied in Figure 6 and 7. It can be seen clearly, that the progressive drops are repeatable behavior in different wells' readings. However, these drops were transferred with a time lag from the near sensor to the furthest sensor from the predetermined sinkhole location. The most likely explanation for this behavior is the internal collapse of the cavities within the sediments, since all other parameters and factors related to sinkhole formation were controlled. One can notice the effect of the sinkhole underground formation in early stage at a groundwater monitoring well located near a progressing sinkhole first. Then this behavior might be transferred to the next monitoring well over a certain time period (time lag). This time duration varies depending on the distance that well is from the progressing sinkhole location. In general, the time lags in the progressive drops could be used to measure the proximity of the sinkhole. This can be achieved in the future by correlating the expected sinkhole time to the progressive drops of the groundwater table.

Finally, it can be noted that the trend of the variation of groundwater levels from all tests showed a good agreement in general. The spatial-temporal model proved that there is a groundwater cone of depression prior to the sinkhole surface collapse. This water cone indicates 


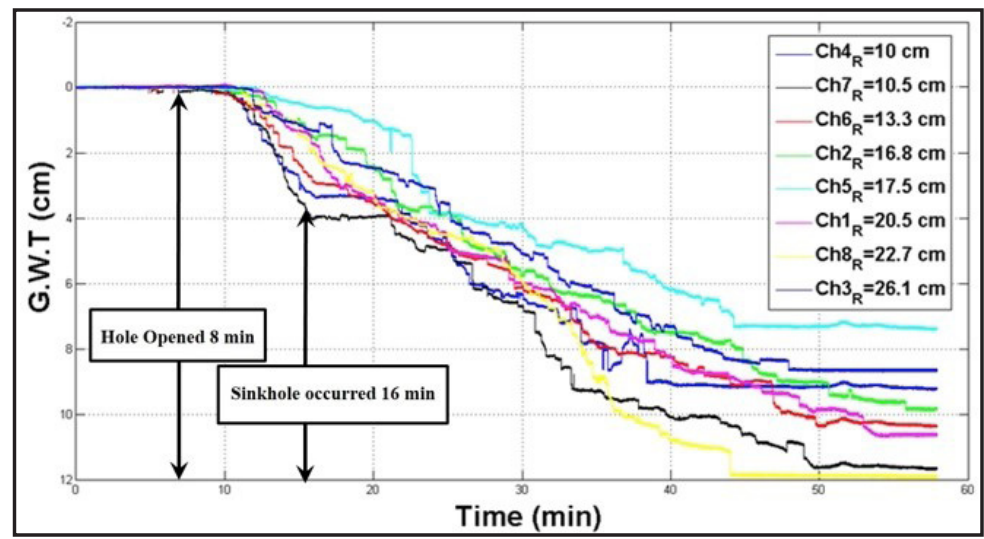

(a) TEST 1

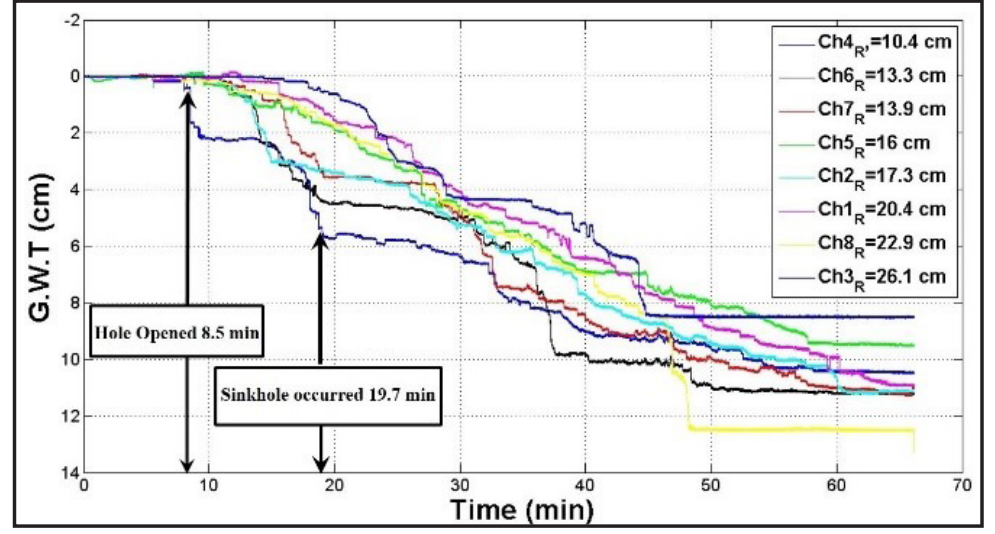

(b) TEST 2
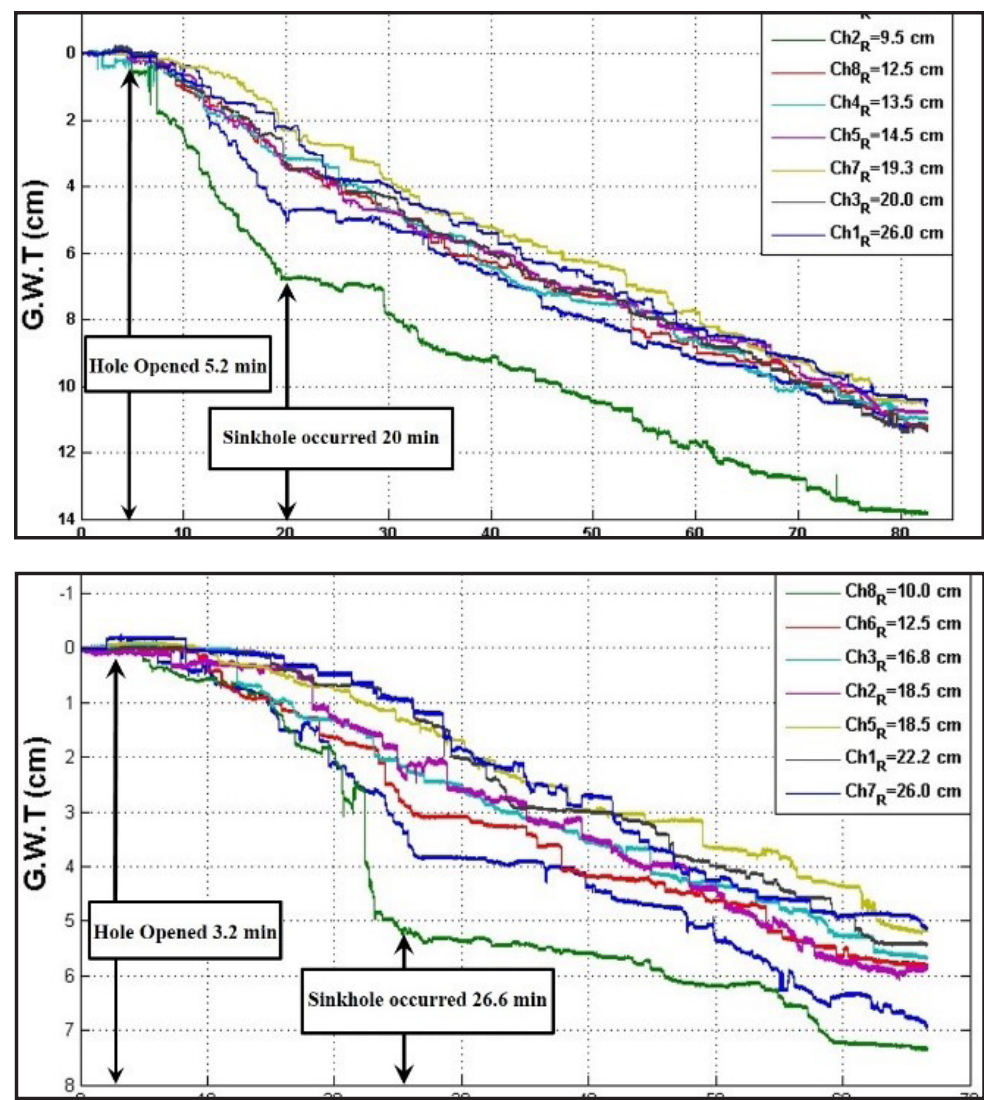

(c) TEST 3

(d) TEST 4

Figure 4. Groundwater level fluctuations with time in the sinkhole physical model test. 


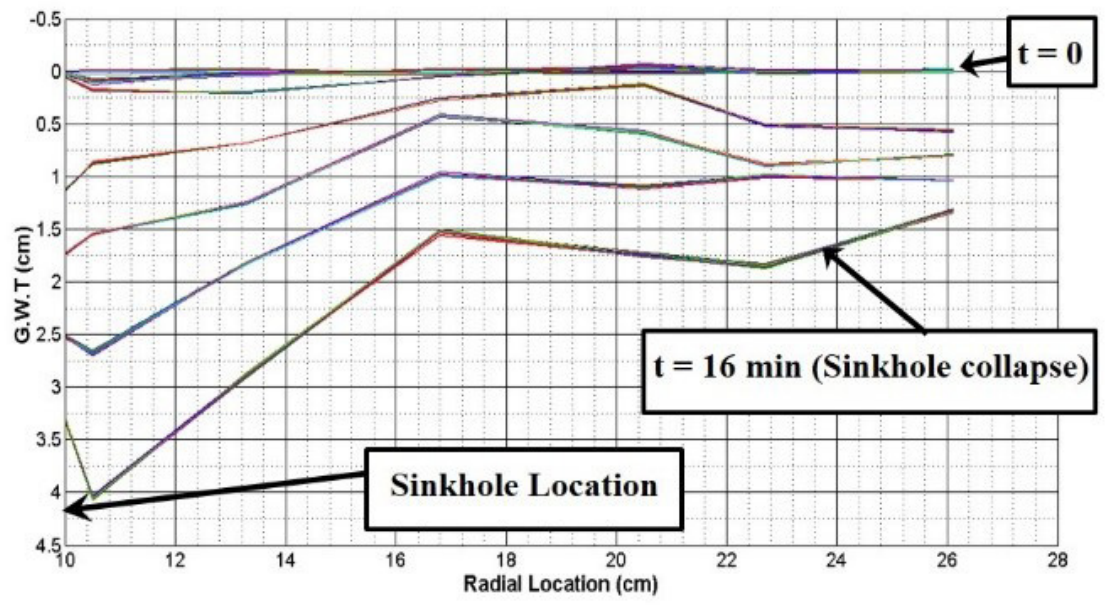

(a) TEST 1

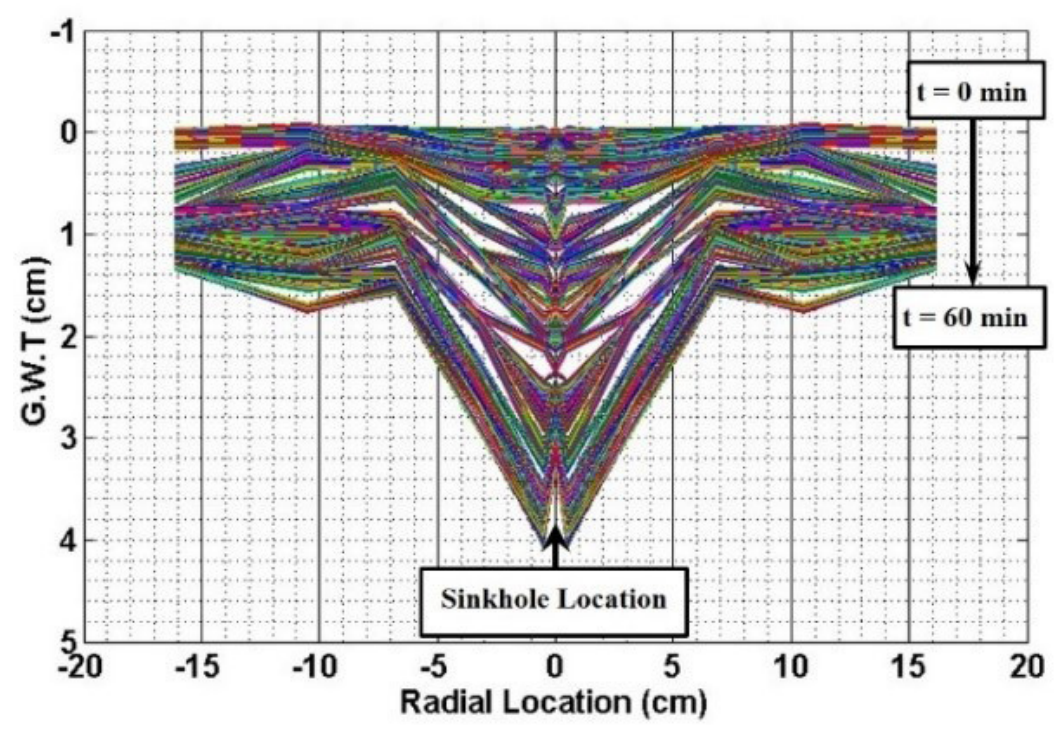

(b) TEST 1

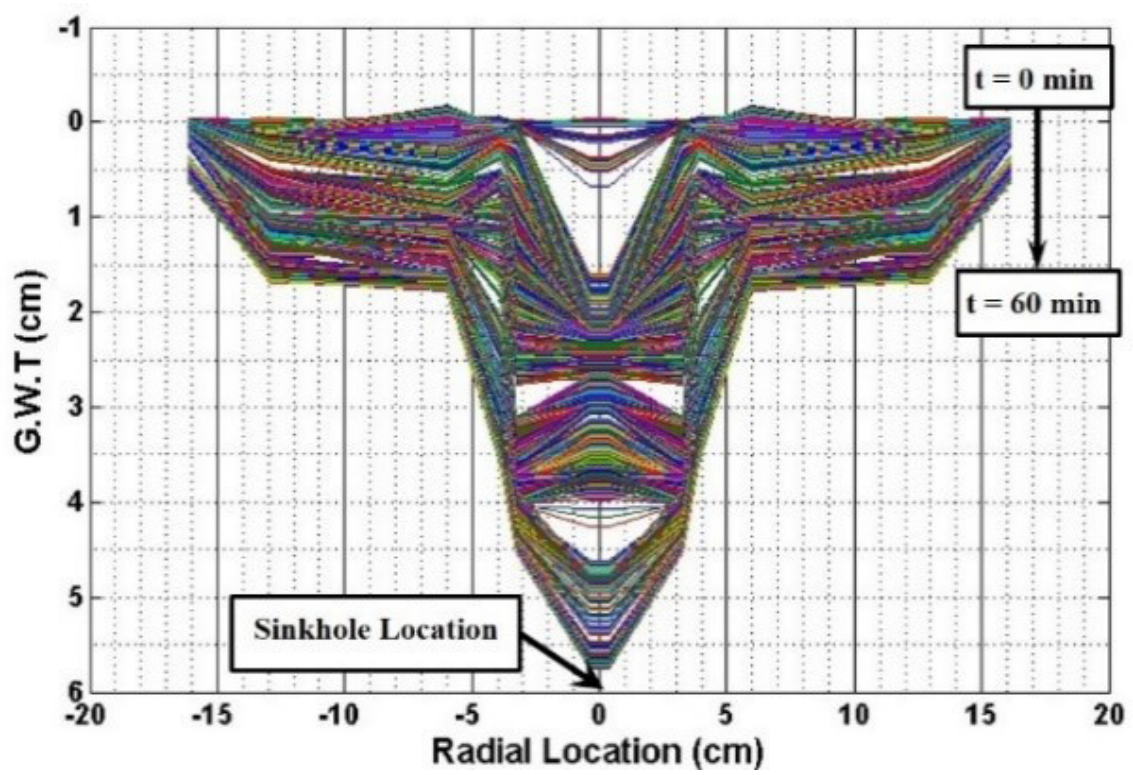

(c) TEST 2

Figure 5. Groundwater selected readings in different times versus the wells radial locations. 
the future potential location of the sinkhole collapse. Also, repeatable groundwater progressive drops were observed in all models. These progressive drops were transferred from one well to another over a certain time period called time lag. Both the progressive drops and their time lags can provide information relevant to the sinkhole locations and their progression rates.

\section{Conclusions}

In this paper, a small-scale sinkhole model used to physically simulate the natural sinkhole collapse and to provide a potential avenue to predict the location of a sinkhole. The sinkhole simulator consisted of two main components: The soil mold and the monitoring system. The monitoring system was used to conduct a spatialtemporal analysis of data collected from a network of groundwater monitoring wells (sensors). These wells were distributed in a radial pattern around a predetermined location of a sinkhole. A different soil levels (overburden soil) and initial groundwater levels were tested in this model. This model has a one circular opening to simulate a crack in the limestone that allows the transfer of a volume of soil through the dissolving bedrock layer. During all tests (more than 30 runs), the fluctuations in the groundwater levels showed a very distinctive trend.

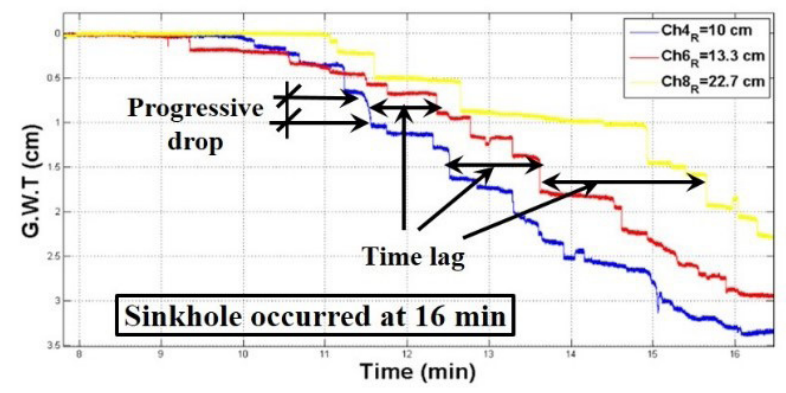

Figure 6. Groundwater table readings at three selected wells locations, TEST 1.

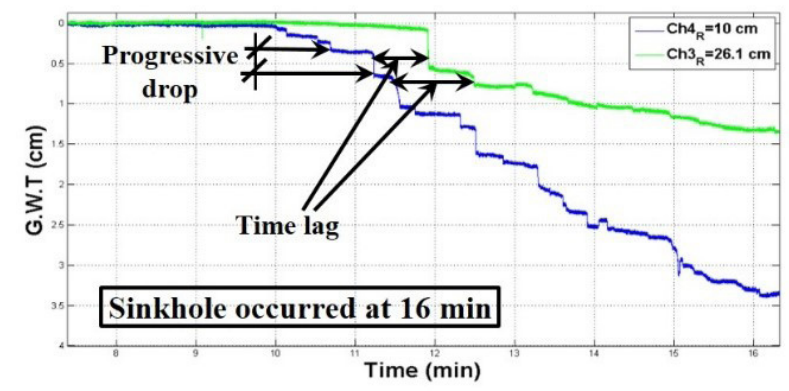

Figure 7. Groundwater table readings at the nearest and furthest monitoring wells, TEST 1.
The level in the wells nearer to the sinkhole always showed water levels lower than the distant wells. This naturally occurring behavior can be referred to as a cone of depression. It can be concluded, that the current physical model was successful in showing the formation of this groundwater cone of depression that occurs before there are any surface signs of sinkholes. This, in turn, in a reverse manner, can be used in predicting the potential location of sinkholes that are forming underground and show no surface indications.

By studying sensor data, some progressive drops were evident, which are consistently seen at the same location over multiple runs. Also, these progressive drops migrate in time from the closer sensor to the sinkhole to the further sensor. This time lag behavior and the corresponding progressive drops are indicators of the potential location of sinkholes. Thus, both the progressive drops and their time lags can help in investigating the sinkhole locations and the sinkhole progressing rate. This can be achieved by correlating an actual progressing sinkhole to the groundwater table fluctuation and progressive drop measurements. This paper presented a simple physical model and more advanced testing is planned.

\section{References}

Abdulla WA, Goodings, DJ. 1996. Modeling Of Sinkholes in Weakly Cemented Sand. ASCE, Journal of Geotechnical Engineering 122 (12): 998-1005.

Atkinson T. 1977. Diffuse flow and conduit flow in limestone terrain in the Mendip Hills, Somerset (Great Britain). Journal of Hydrology 35: 93-110.

Bottrell SH, Ford D, Williams P. 1991. Karst Geomorphology and Hydrology. The Geographical Journal 157 (1): 87.

Caudron M, Emeriault F, Kastner R, Al Heib M. 2006a. Collapses of undergroud cavities and soil-structure interactions: Experimental and numerical models. Proceedings of the 1st Euro mediterranean symposium on advances on geomaterials and structures, Hammamet, Tunisia, p. 311-316.

Caudron M, Emeriault F, Kastner R, Al Heib M. 2006b. Sinkhole and soil-structure interactions: Development of an experimental model. International Conference of Physical Modeling in Geotechnics, Hong Kong, p. 1261-1267.

Caudron M, Al Heib M, Emeriault F. 2008. Collapses of underground cavities and soil-structure interactions: influences of the position of the structure relative to the cavity. Proceedings of the 12th international conference of Int. Association for Computer Methods and Advances in Geomechanics, Goa, India. 
Chen J, Beck B. 1989. Quantitative modeling of the cover-collapse process. Proceedings of the third multidisciplinary conference on sinkholes and the engineering and environmental impacts of karst, St Petersburg Beach, Florida, Balkema, Rotterdam, p 89-95.

Foshee J, Bixler B. 1994. Cover-subsidence sinkhole evaluation of State Road 434, Longwood, Florida. ASCE, Journal of Geotechnical Engineering 120 (11): 2026-2040.

Goodings DJ, Abdulla WA. 2002. Stability charts for predicting sinkholes in weakly cemented sand over karst limestone. Engineering Geology 65: 179-184.

Lei M, Jiang X, Yu L. 1994. The model experiment on karst collapse. In: Proc 7th Int IAEG Congr, Lisboa, p. 1883-1889.

Lei M, Jiang X, Yu L. 2002. New advances of karst collapse research in China. In: Beck BF, Herring JG (editors), Geotechnicat and Environmentat Applications of Karst Geology and Hydrology, p. 145-151.

Lei M, Gao Y, Jiang X, Hu Y. 2005. Experimental Study of Physical Models for Sinkhole Collapses in Wuhan, China. Proceedings of the Tenth Multidisciplinary Conference on Sinkholes and the Engineering and Environmental Impacts of Karsts, ASCE Geotechnical Special Publication, p. 91-102.

Lewelling BR, Tihansky AB, Kindinger JL. 1998. Assessment of the hydraulic connection between ground water and the Peace River, west-central Florida. U.S. Geological Survey Water-Resources Investigations Report 97-4211, 96 p.

Lowe D, Waltham T. 2002. Dictionary of karst and caves. British Cave Research Association Cave Studies 10.

Quinlan JF, Davies GJ, Worthington SR. 1993. Review of groundwater quality monitoring network design. Journal of Hydraulic Engineering 119: 1436-1441.

Sinclair WC. 1986. Sinkhole development from ground-water withdrawal in the the Tampa area, Florida, U.S. Geological Survey. Water resources investigations p. 81-50.

Sinclair WC, Stewart JW. 1985. Sinkhole type, development, and distribution in Florida: U.S. Geological Survey Map Series 110.

Tihansky AB. 1999. Sinkholes, west-central Florida: A link between surface water and ground water. In: Galloway D, Jones DR, Ingebritsen SE, (editors) Land Subsidence in the United States: U.S. Geological Survey, Circular 1182, p. 121-141.
Waltham T, Bell F, Culshaw M. 2005. Sinkholes and Subsidence: Karst and Cavernous Rocks in Engineering and Construction, Berlin, Germany, Springer, p.382.

Williams PW. 2004. Dolines. In: Gunn, J. (editor), Encyclopedia of Caves and Karst Science, New York (NY): p. 304-310. 